\title{
EDITORIAL
}

\section{MIGRANTES AFRICANOS NA AMÉRICA LATINA}

\author{
African Migrants in Latin America
}

Roberto Marinucci*

A identidade latino-americana é marcada pelas contribuições socioculturais dos numerosos grupos de migrantes, voluntários ou forçados, que ingressaram no território no decorrer dos séculos. Entre eles estão os africanos, trazidos à força desde o século XVI, que carregaram consigo cosmovisões, religiões, idiomas, músicas, danças e outros elementos culturais que marcaram e continuam marcando a identidade da região (Seyferth, 2002).

Nas últimas décadas, a América Latina se depara com novas tipologias de imigração africana, caracterizadas por uma expressiva diversificação em termos de motivações, rotas e projetos migratórios. Neste número da REMHU (n. 56), o Dossiê, coordenado junto ao CSEM pelas pesquisadoras Nanneke Winters e Franziska Reiffen ${ }^{1}$, da Universidade Johannes Gutenberg de Mainz (Alemanha), atenta para diferentes aspectos desses novos deslocamentos, com enfoques prioritariamente antropológicos, sociológicos, geográficos, políticos e demográficos. O artigo introdutório do Dossiê (Winters, Reiffen, 2019) de autoria das duas pesquisadoras supracitadas, elucida as abordagens teóricas e as principais contribuições trazidas nos diferentes artigos da seção.

Neste Editorial queremos salientar como as narrativas dos vários textos que compõem o Dossiê apontam para realidades heterogêneas e complexas, em que se entrelaçam fatores estruturais - sobretudo econômicos e políticos -, e fatores subjetivos, marcados por histórias de vida únicas e irrepetíveis. Nessas dinâmicas, que envolvem tanto os países de origem quanto aqueles de chegada, entrelaçam-se mobilidades e imobilidades, deslocamentos e estadias, processos de sujeição e subjetivização (Mezzadra, 2015). A inserção

Editor-chefe da Revista REMHU, Centro Scalabriniano de Estudos Migratórios (CSEM). Brasília DF, Brasil. E-mail: remhu@csem.org.br. Orcid: 0000-0002-2042-2628.

1 Agradecemos as professoras Nanneke Winters e Franziska Reiffen pela colaboração na organização do Dossiê. 
na América Latina se dá pela construção de lugares materiais e existenciais (haciendo-lugar), vinculados a um território específico - físico e social -, mas também com um forte caráter transnacional. Parafraseando Marc Augé (1994, p. 73), os "pontos de trânsitos e as ocupações provisórias", geralmente caracterizados pelo anonimato, a solidão e a ausência de memória, são ressignificados e transformados, na medida do possível, em "lugares" identitários, relacionais e históricos.

A incessante mobilidade geográfica em busca de respostas mais adequadas e coerentes aos desafios pessoais, familiares e estruturais se intersecciona, por vezes, com a (suposta) imobilidade das cosmovisões culturais e religiosas, e seus decorrentes imperativos comportamentais. Nesse processo, as inevitáveis dinâmicas de adaptação e negociação inerentes à construção de novos lugares implicam sempre a reconfiguração de todas as fronteiras, tanto daquelas geográficas quanto daquelas simbólicas (Pace, Ravecca, 2010). Essa dialética entre mobilidades e imobilidades é um dos aspectos que demarca a inserção de migrantes africanos na América Latina.

Além do aprofundamento do fenômeno migratório em termos gerais, o Dossiê auxilia na compreensão das características e da recepção da imigração africana na América Latina. Ademais, a reflexão sobre as diferentes estratégias de "hacer-lugar", abre um importante debate acerca das assim chamadas políticas de "integração" no território, políticas essas frequentemente elaboradas mais na lógica do controle e da segurança do que da promoção da autonomia e dos direitos das pessoas migrantes.

Na Seção "Artigos", Victoria Finn desenvolve uma reflexão teórica acerca da relação entre indivíduo e Estado no interior das dinâmicas migratórias em nível internacional. A autora, mesmo não menosprezando a agency das pessoas migrantes, atenta para o papel protagônico das políticas migratórias estatais, tanto no que diz respeito ao ingresso no território do país, quanto ao assim chamado processo integrativo. Em outros termos, a agency das pessoas migrantes é sempre condicionada pelas "políticas de fronteirização", externas e internas, dos Estados.

Numa abordagem análoga, Federico Rodrigo analisa o papel desenvolvido pelos programas de regularização migratória, tendo como referência específica a migração boliviana para a cidade de La Plana, na Argentina. Na ótica do autor, o acesso à documentação, tanto no país de origem quanto no de chegada, não pode ser lida apenas na ótica do fortalecimento de políticas de controle e securitização, mas também naquela de acesso a direitos e práticas de cidadania. 
A importância da intervenção estatal nos processos de inserção dos imigrantes é também o foco dos últimos dois artigos. Primeiramente, Juliana Chatti lorio e Silvia Garcia Nogueira analisam os processos de acolhimento de estrangeiros - brasileiros e timorenses - em Portugal. O artigo, construído a partir de duas pesquisas, atenta sobre as dificuldades de inserção desses estudantes, provocadas às vezes por expectativas equivocadas ou exageradas por parte dos recém-chegados, outras vezes pelo idioma (sobretudo em relação aos timorenses), por entraves institucionais ou, inclusive, por preconceitos raciais e pela xenofobia.

Finalmente, no último artigo, Menara Guizardi e Pablo Mardones apresentam uma reflexão sobre as configurações migratórias de três Estados da Alemanha. A partir de fontes históricas e demográficas, do auxílio de pesquisadores locais e da observação etnográfica, os autores descrevem três diferentes modelos migratórios e, principalmente, ressaltam o papel central desenvolvido pelo Estado, questionando, dessa forma, "el discurso hegemónico en los países del Cono Sur Americano donde el giro a la derecha se acompaña no solamente de una lógica de demonización del Estado (...), sino también de la aseveración de la idea de que, en lo concierne a la cuestión migrante, la inversión pública debe reducirse a la compra y aplicación de armas de control fronterizo y herramientas de vigilancia de las movilidades humanas" (p. 230).

Na Seção "Relatos e reflexões", Nanneke Winters apresenta um relato do trabalho de campo no Panamá, tendo como foco a migração de trânsito de pessoas africanas, na perspectiva do "haciendo-lugar" retratada no Dossiê da revista. A autora, entre outros aspectos, sublinha a importância da pesquisa em áreas de trânsito periféricas, como as zonas rurais e, inclusive, as comunidades indígenas.

Ainda nessa seção, Igor B. Cunha e Nathalia Fernandes relatam, de forma sucinta, alguns resultados de uma pesquisa realizada pelo Centro Scalabriniano de Estudos Migratórios (CSEM) em Tijuana, México, sobre o trabalho sócio-pastoral de acolhida a mulheres e crianças migrantes no Instituto Madre Assunta das Irmãs Scalabrinianas. A reflexão destaca o assim chamado "atendimento integral", com suas potencialidades e limitações.

A resenha de Fabio Perocco sobre o livro Caporalato. An Authentic Agromafia, de Fiammetta Fanizza e Marco Omizzolo encerra o número da revista.

Desejamos a todas e todos uma boa leitura.

\section{Referências bibliográficas}

AUGÉ, Marc. Não lugares. Introdução a uma antropologia da supermodernidade. Campinas, SP: Papirus, 1994. 
MEZZADRA, Sandro. Multiplicação das fronteiras e das práticas de mobilidade. REMHU, Revista Interdisciplinar da Mobilidade Humana, Brasília, v. 23, n. 44, p. 11-30, 2015.

PACE, Enzo; RAVECCA, Andrea. Religioni, genere e generazioni. Uno sguardo europeo sull'Italia: introduzione. Mondi Migranti, n. 2, p. 43-59, 2010.

SEYFERTH, Giralda. Colonização, imigração e a questão racial no Brasil. Revista USP, São Paulo, n. 53, p. 117-149, março-maio 2002.

WINTERS, Nanneke; REIFFEN, Franziska. Haciendo-lugar vía huellas y apegos: las personas migrantes africanas y sus experiencias de movilidad, inmovilidad e inserción local en América Latina. Introducción al dossier temático REMHU 56. REMHU, Revista Interdisciplinar da Mobilidade Humana, v. 27, n. 56, p. 11-33, 2019. 